SCIENTIFIC REPORT

\title{
The prevalence of pseudoexfoliation syndrome in Chinese people
}

\section{A L Young, W W T Tang, D S C Lam}

Background: Pseudoexfoliation syndrome (PXS) is regarded as rare in people of Chinese ethnicity but the prevalence of this condition is not known. This epidemiology study was conducted to assess the prevalence of PXS in cataract patients and to report the clinical features present.

Methods: Prospective descriptive study conducted in the period from March 1999 to May 2001 in ophthalmology departments in cluster hospitals serving a population of about 1.2 million. 500 consecutive patients aged 60 or above attending the general ophthalmic clinics with a presumed diagnosis of cataract were recruited. A detailed examination including biomicroscopy, intraocular measurement, and gonioscopy were performed on all patients. All positive PXS cases were documented photographically.

Results: 500 patients were examined. They ranged from the ages of 60 to 91 years old, with a male to female ratio of $1: 2$. $40 \%$ suffered from hypertension while $24 \%$ were known diabetics. Only two positive cases $(0.4 \%)$ of PXS were identified in the study population. $18 \%$ of all eyes were found to have narrow angles (defined as grade 0 to 2 by Shaffer grading). Nuclear sclerosis was the single most common type of lens opacity.

Conclusion: PXS is a rare condition in Chinese people. A prevalence rate of $0.4 \%$ in patients aged 60 or above was identified in this hospital based epidemiology study. To the best of our knowledge, this was the first study conducted in a Chinese population to examine the prevalence of PXS.

$\mathrm{P}$ seudoexfoliation syndrome (PXS) was first described in 1917 by Linberg ${ }^{1}$ in a Finnish population. The clinical diagnosis is made by the presence of typical pseudoexfoliation material (PXM) on the anterior capsule surface. In addition to PXM, other features include endothelial pigmentation, loss of pupillary ruff, iris transillumination, Sampaolesi's line, and pigment deposition in the trabecular meshwork. ${ }^{2}$

PXS is associated with various ocular complications. Elevated intraocular pressure and glaucomatous nerve damage had been demonstrated in patients with PXS. ${ }^{3-7}$ Cataracts were reported to be more common in patients with PXS. ${ }^{89}$ Unfavourable factors such as poor mydriasis, ${ }^{10}$ zonular weakness, corneal endotheliopathy, ${ }^{11}$ higher rate of vitreous loss, ${ }^{12}$ capsular phimosis, and opacification have all been reported..$^{13}$

PXM has been identified in various tissues in patients with ocular PXS. ${ }^{14-16}$ Systemic associations reported include angina, hypertension, myocardial infarction, stroke, and abdominal aortic aneurysm. ${ }^{17}{ }^{18}$ The exact aetiology and pathogenesis remain largely unknown. ${ }^{19}$ Hypothesis of an accumulation of basement membrane components such as fibrillin has been proposed..$^{20}$
The prevalence of PXS in various populations were reported to be: England (4\%), Germany (4.7\%), Norway (6.3\%), Eskimos (0\%), Russia (12\%), Finland (22\%), Iceland (29\%), Greece (16.1\%), Australia (0.98\%), and Iran (9.6\%). ${ }^{21-25}$ The clinical, microscopic, and ultrastructural features of PXS in Chinese patients has been described, ${ }^{26}$ but its prevalence has not been previously examined. Although a weak association between PXS and brown irides was described, ${ }^{27}$ it is generally considered as rare in Chinese people. The primary aim of our study is to assess the prevalence of PXS in a Chinese population and to report the clinical features present. In addition, information on angle status and cataract types is documented.

\section{MATERIALS AND METHODS}

Patients with a presumptive diagnosis of cataract attending the general ophthalmic clinics at the Prince of Wales Hospital and Alice Ho Miu Ling Nethersole Hospital in the period of March 1999 to May 2001 were invited to participate in this study. A total of 500 consecutive patients were recruited by one of the authors (ALY). Patients who were over the age of 60 years old, cooperative with examination procedures, and who had no previous intraocular surgery in either eye were included. Informed consent was obtained from all the participants and ethics committee approval was granted. Relevant details in medical and ocular history were obtained from each patient. A complete ocular examination conducted on all patients included intraocular pressure measurement, gonioscopy (not indentation), slit lamp biomicroscopy, and dilated fundus examination. Angle width was assessed and classified as narrow for those with Schaffer grade 0-2 and open for those with grade 3-4. Cataracts were assessed and classified morphologically as follows: nuclear sclerosis (NS), cortical (C), and posterior subcapsular (PSC). PXS was diagnosed clinically by the presence of typical PXM on anterior lens capsule or at the pupil border, with or without Sampaolesi's line and pigment deposition in angle and/or corneal endothelium. All positive cases were photographically recorded.

\section{RESULTS}

Of 500 patients recruited, 315 (63\%) were female and 185 $(37 \%)$ were male; ages ranged from 60 to 91 years old. Approximately three quarters of all participants were over 65 years old (fig 1).

Forty per cent of patients had hypertension while $24 \%$ had diabetes mellitus. The prevalence of hypertension in the local general population had been reported to be $48 \%$ among those aged 70 or above, ${ }^{28}$ while diabetes mellitus in those older than 65 was reported to be about $25 \% .{ }^{29}$ The participants in our

Abbreviations: PXM, pseudoexfoliation material; PXS, pseudoexfoliation syndrome 


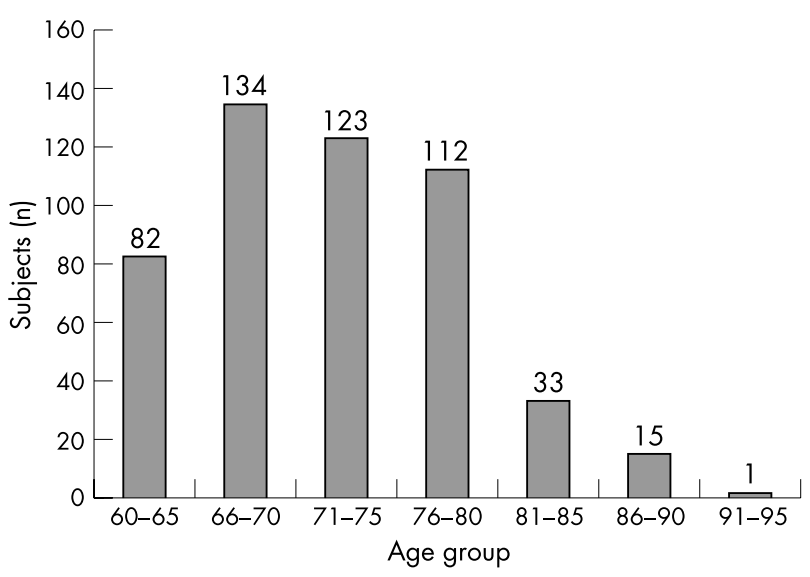

Figure 1 Distribution of ages of study population.

study appeared to be a reasonable representation of the age matched general population.

The distribution of the morphological types of cataract observed is illustrated in figure 2. The most common presentation was mixed cataract with both nuclear and cortical elements ( $>50 \%$ of all cases) while NS was the single most common morphology type (present in 99\%). Cortical and posterior subcapsular opacities were observed in $69 \%$ and $19 \%$ respectively.

Eighteen percent of all eyes were found to have narrow angles. The percentage of narrow angles observed was higher in females than males, at $22 \%$ and $12 \%$ respectively. The difference was statistically significant $\left(\chi^{2}\right.$ of independence: $\left.\chi^{2}=16.62 ; \mathrm{df}=1 ; \mathrm{p}<0.0001\right)$.

Only two out of 500 patients $(0.4 \%)$ were found to have PXS. Both were male and aged 64 and 66 years old respectively. They were clinically diagnosed by the presence of typical PXM on the peripheral anterior lens capsule. Both
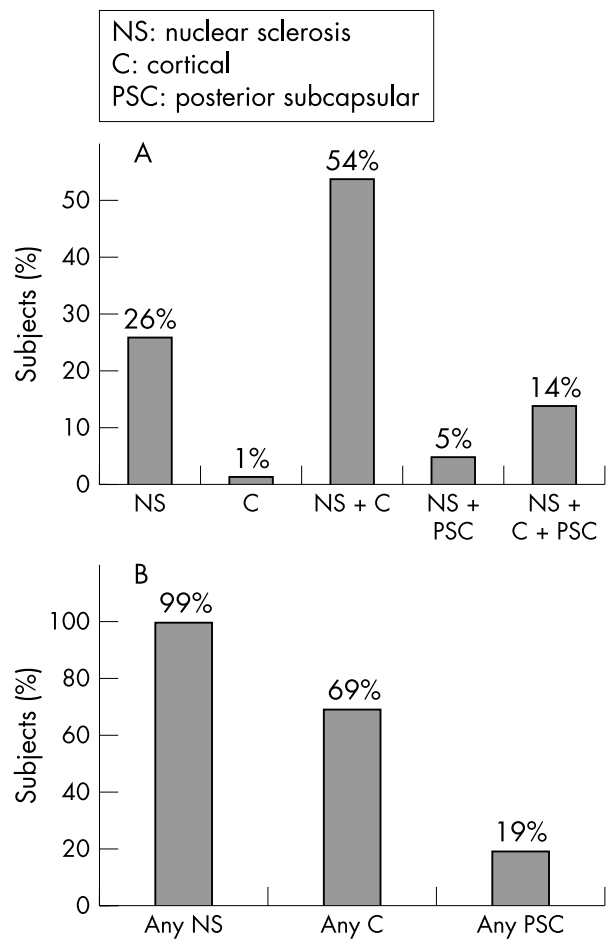

Figure 2 (A) Distribution of lens opacity type on presentation. (B) The relative frequency of cataract types. patients had only unilateral ocular involvement, with the absence of any additional features. The angles were open, and intraocular pressure and cup:disc ratios were found to be normal. Both patients had nuclear sclerosis without any phacodonesis.

\section{DISCUSSION}

Although all cases of PXS in this study were men, no definite sex predominance has been previously shown. ${ }^{2}$ Clinical PXS may present unilaterally, as observed in the two positive cases of this study. Our two cases did not have glaucoma at the time of diagnosis. As PXS has an increased predilection for both open and narrow angle glaucoma, intraocular pressure in both eyes should be regularly monitored. ${ }^{5}{ }^{30}$ Acute angle closure glaucoma is common in Hong Kong and narrower angles were considered to be related. ${ }^{31}$ In this study, $18 \%$ of all included participants had narrow angles, which is much higher in comparison with a prevalence of $3.8 \%$ of narrow angles reported in the Framingham study. ${ }^{32}$

Nuclear sclerosis was the commonest type of lens opacity observed, followed by cortical and posterior subcapsular opacities. The results are similar to findings reported in the Beaver Dam Eye Study ${ }^{33}$ and Framingham Eye Study. ${ }^{34}$ In contrast, cortical opacities were most prevalent in African populations. ${ }^{35}$

Cataracts are known to be more common in PXS. Ascorbic acid is significantly reduced in the aqueous of cataract patients with PXS. ${ }^{36}{ }^{37}$ One may therefore consider the possible association between oxidative stress and UV exposure in PXS and hence the reason for the association between the two. The prevalence of PXS in patients with cataract had been reported to be $17.7 \%, 23.5 \%$, and $28.7 \%$ in Turkey, Portugal, and Spain respectively. ${ }^{10} 3839$ In contrast, our prevalence of $0.4 \%$ ( similar to Eskimos-possibly related to a common ancestry) is much lower in comparison.

One must stress that precise figures on prevalence can only be obtained by studying population groups and that the current small scale hospital based study on patients with cataracts would lead to bias. In addition, the true figure could have been underestimated, as the clinical signs in PXS are known to be subtle in the early stages. Furthermore, it is regarded difficult to detect PXS in patients with cataracts. ${ }^{40}$

In conclusion, PXS is a rare condition in Chinese people with a prevalence rate of $0.4 \%$ in patients with cataract aged 60 or over. To the best of our knowledge, this was the first study conducted in a Chinese population to assess the prevalence of PXS.

\section{Authors' affiliations}

A L Young, D S C Lam, Department of Ophthalmology and Visual Sciences, The Chinese University of Hong Kong, Prince of Wales Hospital, Shatin, Hong Kong, People's Republic of China W W T Tang, Department of Ophthalmology, Tseung Kwan O Hospital, Kowloon, Hong Kong, People's Republic of China

Financial support: supported in part by the Action for Vision Eye Foundation, Hong Kong

Financial interest: none

Correspondence to: $\operatorname{Dr}$ A L Young, Department of Ophthalmology \& Visual Sciences, The Chinese University of Hong Kong, Prince of Wales Hospital, Shatin, New Territories, Hong Kong; asmyoung@netvigator.com

Accepted for publication 7 June 2003

\section{REFERENCES}

1 Lindberg JG. Kliniska undersokningar over depigmenteringen av pupillarranden och genomlysbarheten av iris vid fall av aldersstarr samt $i$ normala ogon hos gamla personer [Thesis]. Helsinki, Finland: Helsinki University, 1917. 
2 Prince AM, Ritch R. Clinical signs of the pseudoexfoliation syndrome. Ophthalmology 1986;93:803-7.

3 Fukisawa K, Sugai S, Inomata H, et al. Relationship between intraocular pressure and age in the exfoliation syndrome. Ophthalmologica 1995:209:199-202.

4 Davanger M, Ringvold A, Blika S. Pseudo-exfoliation. IOP and glaucoma. Acta Ophthalmol 1991;69:569-73.

5 Kjorsvik S, Rossvold I. The middle-Norway eye-screening II. Prevalence of simple and capsule glaucoma. Acta Ophthalmol 1991;69:273-80.

6 Ringvold A, Blika S, Elsas T, et al. Increased occurrence of exfoliation in the male, Spanish American population of New Mexico. J Am Optom Assoc 1992;63:643-8.

7 Konstas AGP, Jay JL, Marshall GE, et al. Prevalence, diagnostic features, and response to trabeculectomy in exfoliation glaucoma. Ophthalmology 1993; 100:619-27.

8 Hirvela H, Luukinen H, Laatikainen L. Prevalence and risk factors of lens opacities in the elderly in Finland. Ophthalmology 1995;102:108-17.

9 Rouhiainen H, Terasvirta M. Presence of pseudoexfoliation on clear and opacified crystalline lenses in an aged population. Ophthalmologica 1992;204:67-70

10 Alfaiate $M$, Leite $E$, Mira J, et al. Prevalence and surgical complications of pseudoexfoliation syndrome in Portuguese patients with senile cataract. J Cataract Refract Surg 1996;22:972-6.

11 Wang L, Yamasita R, Hommura S. Corneal endothelial changes and aqueous flare intensity in pseudoexfoliation syndrome. Ophthalmologica 1999;213:387-91.

12 Lumme $\mathbf{P}$, Laatikainen L. Exfoliation syndrome and cataract extraction. Am J Ophthalmol 1993;116:51-5.

13 Kuchle M, Amberg A, Martus $P$, et al. Pseudoexfoliation syndrome and secondary cataract. Br J Ophthalmol 1997;81:862-6.

14 Schlotzer-Schrehardt U, Kocar MR, Naumann GOH, et al. Pseudoexfoliation syndrome: ocular manifestation of a systemic disorder? Arch Ophthalmol 1992;110:1752-6.

15 Streeten BW, Dark AJ, Wallace RN, et al. Pseudoexfoliative fibrillopathy in the skin of patients with ocular pseudoexfoliation. Am J Ophthalmol 1990;1 10:490-9.

16 Streeten BW, Li Z-Y, Wallace RN, et al. Pseudoexfoliative fibrillopathy in visceral organs of a patient with pseudoexfoliation syndrome. Arch Ophthalmol 1992;109:1757-62.

17 Mitchell P, Wang JJ, Smith W. Association of pseudoexfoliation syndrome with increased vascular risk. Am J Ophthalmol 1997;124:685-7.

18 Schumacher S, Schlotzer-Schrehardt U, Martus P, et al. Pseudoexfoliation syndrome and aneurysms of the abdominal aorta. Lancet 2001;357:359-60.

19 Damii KF, Bains HS, Stefansson E, et al. Is pseudoexfoliation syndrome inherited? A review of genetic and nongenetic factors and a new observation. Ophthalmic Genetics 1998;19:175-85.

20 Schlotzer-Schrehardt U, von der Mark K, Sakai LY, et al. Increased extracellular deposition of fibrillin-containing fibrils in pseudoexfoliation syndrome. Invest Ophthalmol Vis Sci 1997;38:970-84.

21 Aasved H. The geographical distribution of fibrillopathia epitheliocapsularis, so-called senile exfoliation or pseudoexfoliation of the anterior lens capsule. Acta Ophthalmol 1969;47:792-810.
22 Forsius H. Prevalence of pseudoexfoliation of the lens in Finns, Lapps, Icelanders, Eskimos, and Russians. Trans Ophthalmol Soc UK 1979;99:296-8.

23 Kozobolis VP, Papatzanaki M, Vlachonikolis IG, et al. Epidemiology of pseudoexfoliation in the island of Crete (Greece). Acta Ophthalmol Scand 1997;75:726-9

24 Mccarty CA, Taylor HR. Pseudoexfoliation syndrome in Australian adults. Am J Ophthalmol 2000;129:629-33.

25 Nouri-Mahdavi K, Nosrat N, Sahebghalam R, et al. Pseudoexfoliation syndrome in central Iran: a population-based survey. Acta Ophthalmol Scand 1999;77:581-4.

26 Ye T, Mao W, Zhang J. Pseudoexfoliation syndrome in Chinese. Jpn J Ophthalmol 1989:33:300-10.

27 Meyer E, Haim T, Gidoni O, et al. Pseudoexfoliation: epidemiology, clinical and scanning electron microscopic study. Ophthalmologica 1984; 188:141-7.

28 Woo J, Ho SC, Yuen YK, et al. Prevalence and effectiveness of treatment for hypertension on cardiovascular morbidity and mortality in an elderly population aged 70 years and over. Arch Gerontol Geriatr 1997;25:159-65.

29 Janus E. The Hong Kong Cardiovascular Risk Factor Prevalence Study Group. Epidemiology of cardiovascular risk factors in Hong Kong. Clin Exp Pharmacol Physiol 1997;24:987-8.

30 Gross FJ, Tingey D, Epstein DL. Increased prevalence of occludable angles and angle-closure glaucoma in patients with pseudoexfoliation. Am J Ophthalmol 1994;117:333-6.

31 Lai JSM, Liu DTL, Tham CCY, et al. Epidemiology of acute angle-closure glaucoma in the Hong Kong Chinese population: prospective study. Hong Kong Med J 2001;7:118-23.

32 Leibowitz HM, Krueger DE, Maunder LR, et al. The Framingham Eye Study monograph. Surv Ophthalmol 1980;24(suppl):335-610.

33 Klein BEK, Klein R, Lee KE. Incidence of age-related cataract. The Beaver Dam Eye Study. Arch Ophthalmol 1998;116:219-25.

34 Sperduto RD, Hiller R. The prevalence of nuclear, cortical and posterior subcapsular lens opacities in a general population sample. Ophthalmology 1984;91:815-18

35 Leske MC, Connell AMS, Wu SY, et al. Prevalence of lens opacities in the Barbados Eye Study. Arch Ophthalmol 1997;115:105-11.

36 Koliakos GG, Konstas AG, Schlotzer-Schrehardt U, et al. 8-Isoprostaglandin F2a and ascorbic acid concentration in the aqueous humour of patients with exfoliation syndrome. Br J Ophthalmol 2003;87:353-6.

37 Koliakos GG, Konstas AG, Schlotzer-Schrehardt U, et al. Ascorbic acid concentration is reduced in the aqueous humor of patients with exfoliation syndrome. Am J Ophthalmol 2002;134:879-83.

38 Yalaz M, Othman I, Nas K, et al. The frequency of pseudoexfoliation syndrome in the eastern Mediterranean area of Turkey. Acta Ophthalmol (Copenh) 1992;70:209-13.

39 Moreno Montanes J, Alcolea Paredes A, Campos Garcia S. Prevalence of pseudoexfoliation syndrome in the northwest of Spain. Acta Ophthalmol (Copenh) 1989:67:383-5

40 Krause U, Tarkkanen A. Cataract and pseudoexfoliation. A clinicopathological study. Acta Ophthalmol (Copenh) 1978;56:329-34. 